\title{
Digital 3D Control Room for Healthcare
}

\author{
Liala Baiardi, Andrea Ciaramella and Ingrid Paoletti
}

\begin{abstract}
The building process is in an evolutionary phase dictated by the constructive innovations and the digital revolution that has involved the tools and the technical and design contents of the entire life cycle of buildings. In this context, the operators of the sector need to develop organizational models capable of protecting and managing the conceptual and scale transition, between the conceptual framework of the architecture and the subsequent ones of construction, use and management. In the development of complex projects the elaboration of the organizational model is in fact fundamental to reach adequate figurative, performance and qualitative levels by incorporating the necessary contents of environmental, economic and management sustainability of buildings. This text illustrates the development of a horizontal organizational model for the smart and dynamic control of complex buildings through the creation of an innovative digital Web-Based platform capable of integrating Building Information Modeling (BIM) technology with a "Facility Management platform". The project involves experimentation applied to a real case involving the restructuring of a complex building.
\end{abstract}

Keywords Process approach $\cdot$ Building automation $\cdot$ BIM $\cdot$ Facility management $\cdot$ Interoperability

\section{The Role of Digital Technologies in the Construction Process}

Digital technologies have fundamentally transformed our interactions with the built environment. Mobile devices provide a means to rapidly access and share information. Within the facilities context, these technologies impact both capital project delivery and day-to-day operations (McArthur and Bortoluzzi 2018).

L. Baiardi $(\varangle) \cdot$ A. Ciaramella $\cdot$ I. Paoletti

Architecture, Built Environment and Construction Engineering-ABC Department,

Politecnico di Milano, Milan, Italy

e-mail: liala.baiardi@polimi.it 
In the management of advanced construction processes, the BIM (Building Information Modeling) can play an active role throughout the entire life cycle, giving the possibility of having a single integrated system able to collect and manage information concerning the building or infrastructural object.

One of the topics that the research and innovations focus on in the field of BIM (Building Information Modelling) systems is the creation of tools capable of moving the management and control of design projects onto interoperable platforms. Based on this principle is the ability to manage, by means of the exchange and sharing of complex data and multidisciplinary knowledge, the activities and roles of the various operations involved in the programming, design and management process of these interventions. In particular, within the context of new construction or retrofitting interventions in complex buildings (as is the case for the large healthcare districts), the possibility of developing design models capable of simulating alternative conditions and gauging the effects, guaranteeing a shared feedback, is an essential condition for optimizing management activities during the entire lifecycle of buildings (Di Giulio et al. 2017).

Now the application of methodologies, protocols and BIM tools in the design stage (and even more so in the subsequent phases of the building process) is to be considered no longer an innovation but rather a key element of the whole process (Simeone 2018).

BIM concerns issues of information sharing, interoperability, and efficient collaboration throughout the life cycle of a building, from feasibility stages to the demolition and recycling stages (Isikdag 2015) and now it is seen as a solution for sharing data among multiple systems (Utica 2010). At the same time, the 3D digital approach provides support to the synergic management activity through the high accessibility of a 3D environment.

Recent research efforts have focused on investigating building information modeling (BIM) implementation and its potential expected benefits in project management operations and maintenance (O\&M) (Eastman et al. 2011), including facility management, maintenance, and energy management (Becerik-Gerber et al. 2012; Eastman et al. 2011; Motawa and Almarshad 2013; Teicholz 2013).

Based on these premises, the text, starting from the principles underlying the development, experimentation and innovation project, selected and financed by the Lombardy Region within the Smart Living program, describes the project "digital 3D control Room for Healthcare".

The principles of the research project are in line with the H2020 community strategy, aimed at intelligent, sustainable and inclusive synergies with the research activities carried out in this area by Universities. 


\subsection{The Digital 3D Project}

BIM plays a fundamental role in improving current design and building management practices, contributing to the sustainable implementation of performance levels in terms of creation and management of the built environment.

BIM systems make it possible to draw great benefits in the wide-ranging actions of programmable interventions on public and private building heritage.

The potential of the system is the ability to elaborate complex actions even during the planning of the interventions, contributing to the selection of the most suitable operational paths. Moreover it allows for the model's implementation during the management phases thus the library of the elements can also grow exponentially.

Thanks to BIM coordination it is possible to implement systematic actions aimed at identifying any project problems (with their respective coordinates and associated data) following their corrections until they are resolved and the main deliverables are reached:

- design models related to individual disciplines (e.g. structural, systems, etc.) coordinated with a predetermined level of detail;

- space and circulation programs;

- cost plan and financial information;

- collection and verification of concessions and authorizations;

- assessment of possible procurement strategies and supply chain management issues;

- acceptance and approval of the project by the client.

During the life cycle of a project, the BIM model is progressively enriched with data and information, it is possible to update information relating to design, engineering, construction and economic aspects along with costs.

Fundamental importance is also given to the integration with the sensor network and the building management system (RICS 2014).

The Digital 3D project was developed with the aim of outlining an operational model for intelligent and dynamic building control by relating the executive project to process innovation relating to the Facility Management (FM) operating mode. The model is based on the interoperability of data, in a coordinated form, starting from the design stage and involving the entire process, on several levels.

The innovative aspects are augmented by the building management and personal services model (property and facility and Building automation) which obliges us to rethink the entire building process from design, to construction, to management with a systemic approach.

The interoperability of the management and control tools of the design process is one of the themes on which research and innovations in the field of BIM modeling systems (Building Information Modeling) are focused.

The experimentation and validation of the new model was carried out by applying it to a real case of restructuring of a complex building, a hospital building, and involved the creation of an innovative digital Web-Based platform that integrates BIM technology with an FM platform. 


\section{The Elaboration of the Digital 3D Model}

The development of the Digital 3D model takes its cue from the international principles inherent to the methods of maturation and use of BIM in the design, construction and management phases of built environments. Among the main ones there is the BIM Policy (BIM report 2012) of the British government which introduced the concept of GSL (Government Soft Landing) in order to favor a closer alignment of the design and construction phases with that of management and asset management. GSL guarantees the centrality of the property from the planning and construction phases up to its delivery and management.

The ramp representation of the BIM Maturity Diagram (Richards 2010) shows a systematic transition of BIM maturity levels (Fig. 1).

At "level 0", the project is fundamentally based on paper which of course provides two-dimensional (2D) information.

"level 1" marks a transition from a paper environment to a 2D and 3D environment.

At "level 2" sometimes called "pBIM", we move to a common method of producing, exchanging, publishing and storing information. At the same time, the inclusion in the smart model and additional metadata begins. Being proprietary models focused on individual disciplines. Model integration is based on a Common Data Environment (CDE).

At "level 3" a fully integrated "iBIM" is reached, marked by the use of a single model accessible by all team members. This level of BIM uses 4D, 5D and 6D (management of the life cycle of the building, Facility Management). The 4D environment includes the planning and management of construction phase times,

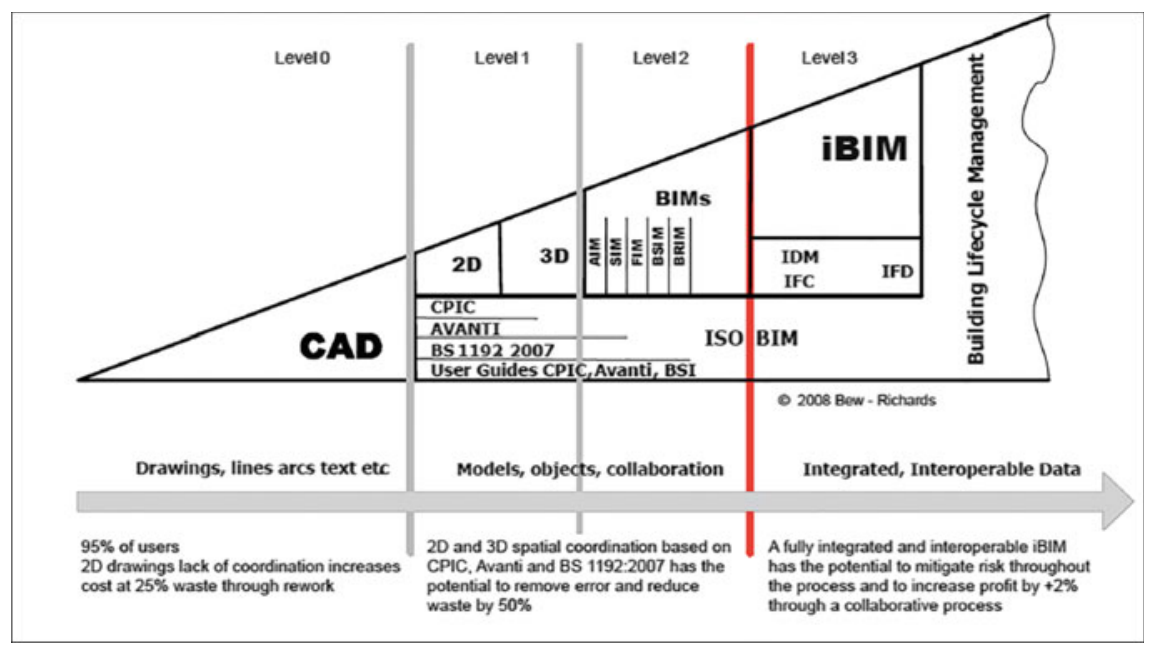

Fig. 1 The BIM maturity model by Bew and Richards (Richards 2010) 
including logistics and site operations. The 5D adds cost management and the possibility of performing economic forecasting analysis and contains technical/economic information such as quantity, unit costs and total materials. The $6 \mathrm{D}$ environment extends the model to Facility Management.

If updates are correctly carried out based on developments in the work phase, the "as built" model is obtained upon completion of the work. This contains all the management and maintenance specifications, useful for future maintenance. It will also be possible to monitor the costs of a building's life cycle and optimize its efficiency and evaluate the costs/benefits of any proposed updates.

An example of application of BIM systems to the management of public real estate assets is the model developed in Finland by Senate Properties, a government body run by private individuals under the patronage of the Finnish Ministry of Finance and responsible for the management of real estate of the government and of the rent of the constituent premises of a patrimony of approximately 10 thousand buildings, for a total of approximately 7 million $\mathrm{m}^{2}$.

Since 2001, Senate Properties has developed a fair number of pilot projects for the adoption of BIM for property management. For construction work on their buildings and for new constructions (for operations of recovery or restoration), the company has decided to request models in IFC ${ }^{1}$ format (Industry Foundation Classes). The implementation of the projects through parametric systems has improved the level of compliance of the overall costs, and the feasibility of the projects to their set objectives.

\section{Interoperability System of the Model}

Of fundamental importance, for the success of the project, is the interoperability of BIM with the FM management system and with the network of sensors and the building given by the software and hardware capacity, on multiple IT platforms (of different origin) in order to exchange information in a useful and reliable way. The efficiency of BIM therefore lies in its interoperability, that is, the ability to allow for the management and communication of electronic data of different types (graphic data, text data and related data) between the various participants in the design, engineering and construction activities, maintenance and related business processes.

To promote interoperability we chose to use an open and publicly managed scheme (dictionary) with a standard language. A common example of a scheme is that conceived by BSI (Building SMART International) and by COBie (Constructions Operations Building Information Exchange) in order to allow for the representation and the public and open exchange of data, in the built environment sector.

\footnotetext{
${ }^{1}$ Industry Foundation Classes (IFC) for data sharing in the construction and facility management industries is the international openBIM standard, registered by the International Standardization Organization (ISO).
} 
COBie is a standardized open-ended approach aimed at facilitating the interoperability of essential information in the BIM process (Fig. 2).

The approach focuses on entering data when created during the design, construction and commissioning phases of the structure. The acquired data is recorded in neutral format and can be exchanged between the various players in IFC format (Industry Foundation Classes).

The basic structure of Digital 3D solves the limitation of the COBie standard given by the object-oriented work environment (Object Oriented Modeling). In this perspective the definition of the minimum and maximum units of components may not coincide with the structuring of the model in the maintenance phase, which, in the case of complex structures, may require groups of objects.

Through the "Open Control Room" interface, the following is available:

- mapping of maintenance events over time, scheduled or one-time ex-post;

- possibility to attach documents;

- reading of the direct properties of the object;

- mirroring of the main data set on local parameters, to allow the generation of display filters;

- construction and writing of values in parameters shared between the two BIM-FM platforms;

- construction of "maintenance routes";

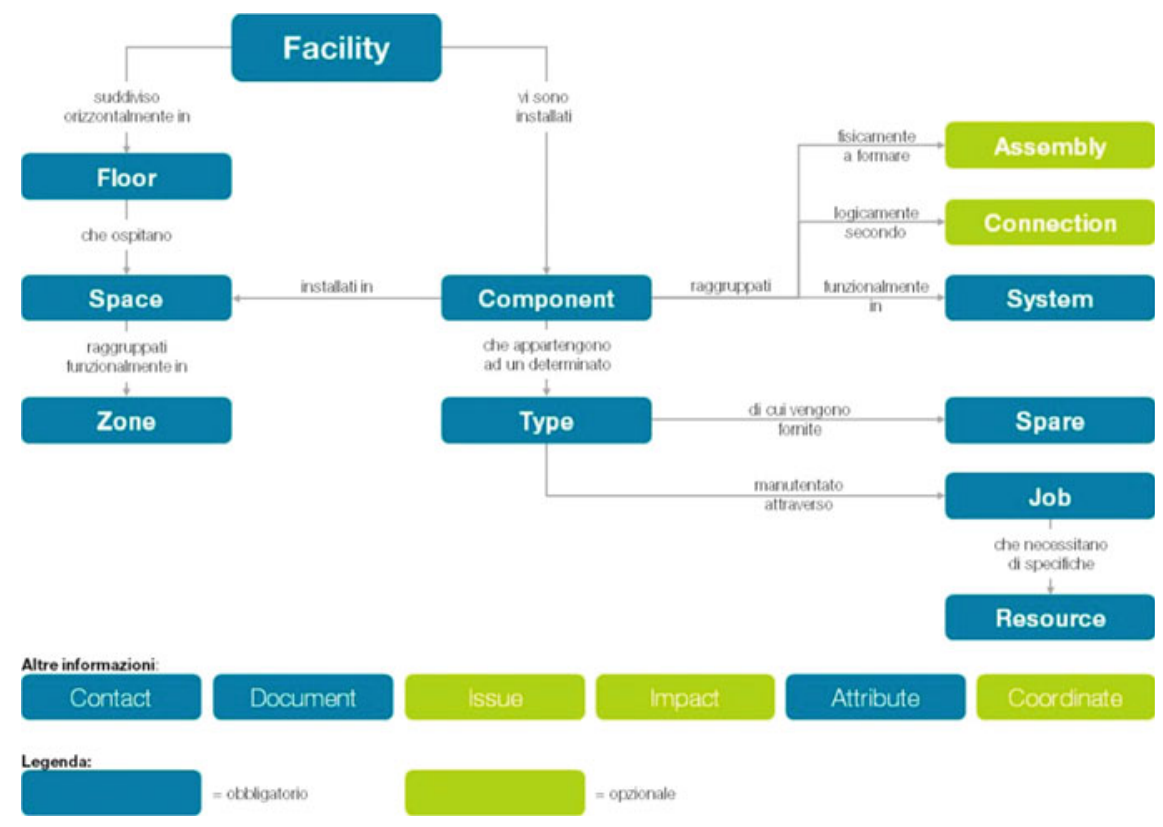

Fig. 2 Example of data structure of the COBie standard. Authors: BIS-LAB, Contec Verona [Further information available on http://www.gruppocontec.it/ ricerca-per-la-progettazione-bis-lab/] 
- mapping of inspections as memorization of sequences of rooms over time, directly in the timeline.

The results of the BIM + FM integration are represented by the "Open Control Room", an evolution of what in today's evolved construction sites is the "BIM Room". The "Open Control Room" represents a "model reference" where access to the Big Data model is mediated by "Agents".

Agents are professionals capable of activating the relationships between data and providing continuous feedback to internal and external operators.

The platform used by the Agents will record, in a rapid, structured and interactive manner the technical/energetic, cadastral, accounting, tax, maintenance and guarantee data, with the following specifics:

- cloud integration of a "networked" 3D shared environment and the concept of an "Internet of Computer" (IoC), which aims to make each building "a sender of itself", networked with others;

- web consultation (via browser without specific plug-ins/software);

- navigable and three-dimensional view of the building: this will allow us to isolate information on consumption, costs, maintenance histories, scheduled maintenance, potential for efficiency, etc. with 3D Data Visualization displays;

- monitoring of people's accesses and behaviors through geolocation;

- semantic query system;

- data return by type of user.

The integration of the BIM and CAFM software has involved the elaboration of a single software architecture able to return the combined and navigable data on the building, with a different level of detail and interaction.

An analysis was then carried out on the two sides (BIM and FM) to perform a "match" between the classification of executive project objects and the classification of "maintenance elements", referring to the long history of standardization and study of the sector, and to the COBie model. The control room can be connected to a large amount of data, improving the decision-making power of the actors that make up the project and management team. The project can be facilitated by real time data sources, marketing data, data coming from the sensors, data on the cloud, stratifications on safety and user preferences.

The key object of the developed interface is to form a "timeline", with a customizable shape and extension, which allows it to "map" over time and spatially a series of events that can be external or internal to the system and that synthetically produce the planned or dynamically mapped life. Moving in the timeline means moving in the building that becomes the spatial reference of events. The chosen graphic wants to highlight the concept of dynamic "database building", which obviously also allows for the use of information of various kinds, for users more directly oriented towards a textual display.

To the functions of integration between databases, the system therefore adds those of direct online interaction, today largely excluded by viewing interfaces, to which the Digital 3D Control Room project adds the possibility of dynamic generation 


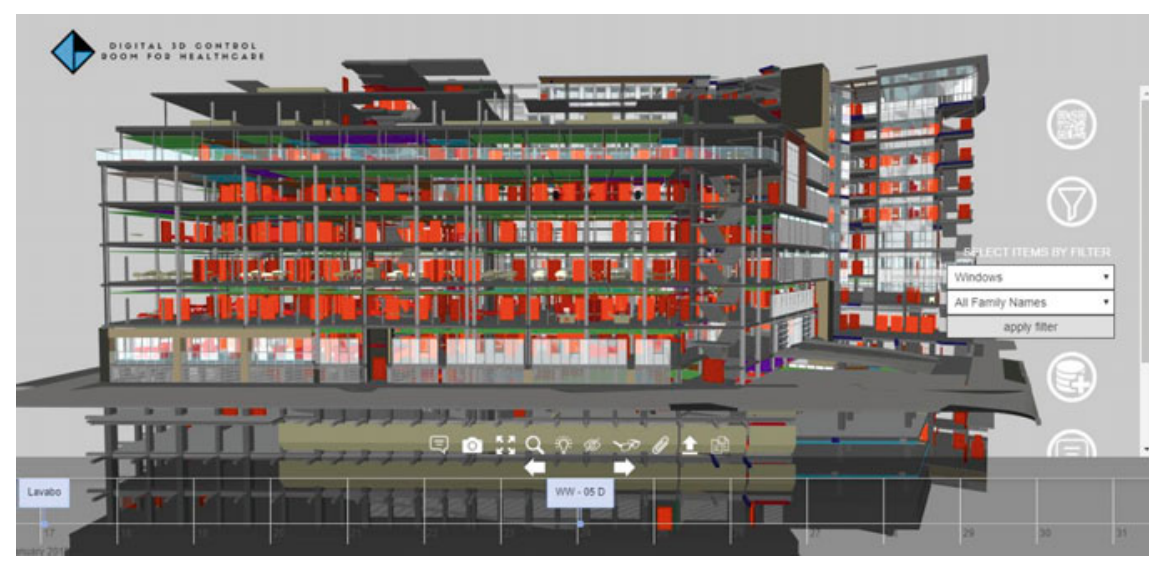

Fig. 3 Example of processing the case study on the Open Control Room online model. Authorship

of maintenance elements, allowing for multiple assignments and the creation of maintenance elements starting from the model (Fig. 3).

Functions of management and a simulation of inspections are then added, made viewable in the timeline both as single events and in sequence. In this sense, a work of mapping the rooms in the floors allows them to be used as a key for physical positioning in 3D vision by framing the identified maintenance object. By clicking on the interested part, the model "moves" to go there showing, in addition to the local data, the detailed photos, memorized according to its timeline, of the reference room/environment.

The system aims to consider two more aspects of the maintenance activity: the synthetic and synergic visualization of the data, and the physical inspection, in sequence, of "visual mapping" (Fig. 4). In this sense, the referencing of photos over time is associated with the maintenance tour for rooms, which allows reading by time key (the tour) and by spatial key (all the photos of this room over time, etc.).

From the Control Room the Operators have access to a customized Web Application that governs the structures, monitors them via webcam, commands or controls the automations, launches the applications and supports the customers.

The web application stores data in a database. Via PC or tablet users can interact with the control room with a dashboard for the control of electronic functions.

The Internet of Things (IoT) makes it possible to measure objects (information provision) but also detect and (or) remotely control them through the existing network infrastructure, creating opportunities to regulate or activate or deactivate systems remotely. 


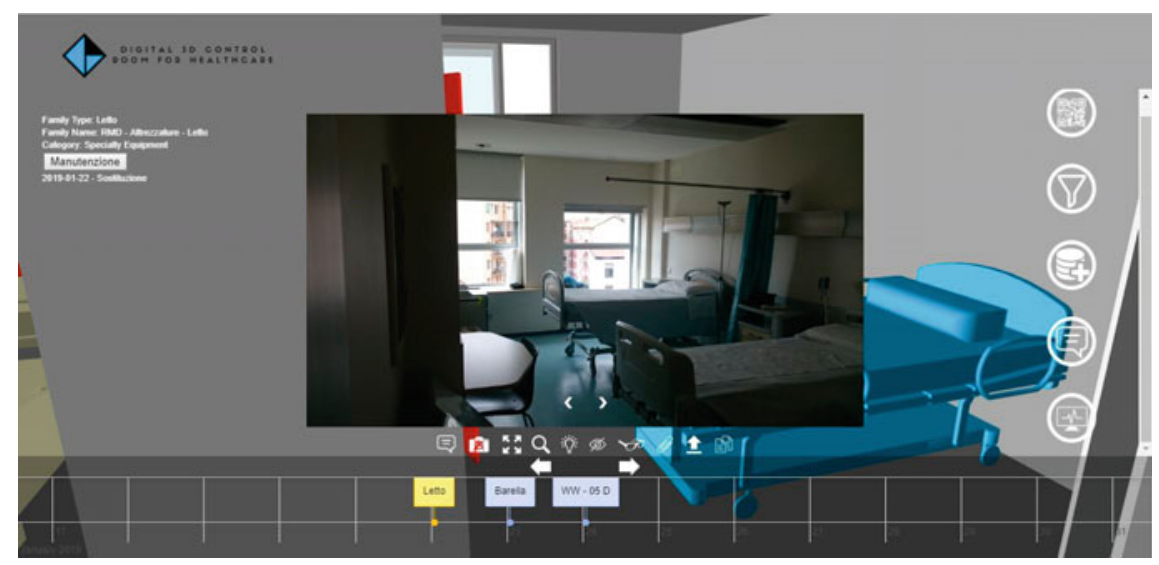

Fig. 4 Example of direct online integration on the Open Control Room model of the "maintenance tour". Authorship

\section{Final Considerations}

The innovation of the management model (facility and property) involves the rethinking of the entire building process, from design, to construction, to maintenance. The approach of the initiative is systemic and sees all the elements participating in a systemic and interdependent way.

The combined synergy between intervention on an existing building with attention to the principles of circular economy (considering for example carbon dioxide emissions, waste, etc.) promotes and guarantees the implementation of the principles of inclusion, safety, well-being, health, eco-sustainability, smart supply chain, recovery and re-use of buildings.

With the emergence of technologies associated with the Smart Built Environment (SBE) concept, in which intelligent objects are connected and interact with integrated installations, it is necessary to study the role that BIM can play in this context, helping to increase the efficiency, safety, and user comfort of future intelligent buildings.

A further integration with mobile applications can orient the building process towards cloud based management where the information of a project is made available at any time, addressing specific applications for Field Management.

This way it is possible to improve the efficiency of the process through suitable IT tools that allow operators to generate a circular flow that supports the control and management reducing repetitions, redundancies and manual transcriptions by the professionals involved.

Acknowledgements The development, experimentation and innovation project entitled "Digital 3D" were selected and financed by the Lombardy Region under the Smart Living program. Project partners: Politecnico di Milano, ABC Department, Rimond S.r.l., Tecnosys Italia S.r.l. Politecnico 
di Milano work group: Andrea Ciaramella, Ingrid Paoletti, Liala Baiardi, Giulio Barazzetta, Stefano Bellintani, Domenico Chizzoniti, Marzia Morena and Valentina Puglisi.

\section{References}

Becerik-Gerber B, Jazizadeh F, Li N, Calis G (2012) Application areas and data requirements for BIM-enabled facilities management. J Constr Eng Manag 138(3):431-442

Di Giulio R, Turillazzi B, Marzi L, Pitzianti S (2017) Integrated BIM-GIS based design for high energy efficiency hospital buildings. Techne (13):243-255. https://doi.org/10.13128/techne19728

Eastman C, Teicholz P, Sacks R, Liston K (2011) BIM handbook: a guide to building information modeling for owners, managers, designers, engineers and contractors. Wiley, Hoboken, NJ

Isikdag U (2015) BIM and IoT: a synopsis from GIS perspective. In: Joint international geoinformation conference, vol. 10, Kuala Lumpur. International archives of the photogrammetry, Kuala Lumpur, pp 33-38

McArthur JJ, Bortoluzzi B (2018) Lean-Agile FM-BIM: a demonstrated approach. Facilities 36(13/14):676-695

Motawa I, Almarshad A (2013) A knowledge-based BIM system for building maintenance. Autom Constr 29:173-182

NBS (2012) National BIM report 2012, NBS, Newcastle. www.bimtaskgroup.org/wp-content/ uploads/2012/03/NBS-NationalBIMReport12.pdf. Accessed 21 February 2019

Richards M (2010) Building information management: a standard framework and guide to BS 1192. BSI Standards, London, UK

RICS, (2014) International BIM implementation guide, Produced by the International BIM Working Group of the Royal Institution of Chartered Surveyors. London, UK

Simeone D (2018) BIM and behavioural simulation for existing buildings re-use design. Tema 4(2). https://doi.org/10.17410/tema.v4i2.188

Teicholz P (2013) BIM for facility managers. Wiley, Hoboken, NJ

Utica G (2010) Tecniche avanzate di gestione dei progetti. McGraw-Hill, Città di Castello, IT 
Open Access This chapter is licensed under the terms of the Creative Commons Attribution 4.0 International License (http://creativecommons.org/licenses/by/4.0/), which permits use, sharing, adaptation, distribution and reproduction in any medium or format, as long as you give appropriate credit to the original author(s) and the source, provide a link to the Creative Commons license and indicate if changes were made.

The images or other third party material in this chapter are included in the chapter's Creative Commons license, unless indicated otherwise in a credit line to the material. If material is not included in the chapter's Creative Commons license and your intended use is not permitted by statutory regulation or exceeds the permitted use, you will need to obtain permission directly from the copyright holder.

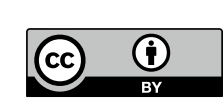

